\section{Early Flowering Induction in Golden Camellia Seedlings and Effects of Paclobutrazol}

\author{
Xiao-Juan Wei, Jinlin Ma, Kun Wang, Xiao-Jing Liang, Jin-Xuan Lan, \\ Yue-Juan $\mathrm{Li}$, and Kai-Xiang $\mathbf{L i}^{1}$ \\ Guangxi Key Laboratory of Characteristic Non-wood Forest Cultivation and \\ Utilization, Guangxi Forestry Research Institute, Nanning, Guangxi 530002, \\ People's Republic of China \\ Haiying Liang ${ }^{1}$ \\ Department of Genetics and Biochemistry, Clemson University, Clemson, SC \\ 29634
}

Additional index words. flowering induction, exogenous phytohormone, golden camellia flower, medicinal plant

\begin{abstract}
Camellia chrysantha flowers are in great market demand as a result of their high ornamental and medicinal values. To induce early flowering in 4-year-old juvenile $C$. chrysantha seedlings, three levels of paclobutrazol (PBZ) concentration $(100,200$, and $300 \mathbf{~ p p m}$ ) were applied to the roots. $P B Z$ is a triazole-type cytochrome $P_{450}$ inhibitor that was found successful in inducing flowering in juvenile $C$. chrysantha grafted plants in a prior report. The current study shows that all three $\mathrm{PBZ}$ concentrations were equally effective in induction of floral buds, resulting in an average of 20 floral buds per treated plant. In comparison, none of the untreated plants flowered. Although the induced flowers were smaller than the ones from mature trees, PBZ treatment did not affect $C$. chrysantha flowers' medical values, because there was no significant change in the content of pharmacologically active compounds (polysaccharide, polyphenols, flavonoids, and saponins). None of the $P B Z$ treatments had a negative effect on the current year's growth in height and basal diameter, photosynthesis, and levels of water-soluble sugars and nutrients [phosphorus $(P)$, nitrogen $(N)$, potassium $(K)$, and carbon $(C)]$. It is concluded that PBZ is an effective flowering inducer for juvenile $C$. chrysantha plants. It was also found that PBZ-treated plants experienced defoliation, and there existed a strong correlation between severity of defoliation and PBZ concentration. This might be attributed by the stress induced by $\mathrm{PBZ}$, as demonstrated by the increased activities of some of the stress-related enzymes [ascorbate peroxidase (APX), catalase (CAT), superoxide dismutase (SOD), and peroxidase (POD)], and the level of malondialdehyde (MAD). Considering that severe defoliation can cause stunted or malformed plants and reduce aesthetic value, $100 \mathrm{ppm}$ is the optimal $\mathrm{PBZ}$ concentration for flowering induction in $C$. chrysantha seedlings.
\end{abstract}

Camellias are well-known worldwide as ornamental plants. The common flower colors are exclusively limited to red, pink, and white. In contrast, yellow camellias, which have golden yellow petals and are also collectively known as golden camellias, are rare in the world. This group of yellowflowering camellias consists of 42 species and five varieties, distributed naturally in a narrow region of southern China and northern Vietnam (Zhuang, 2008). In addition to their

Received for publication 17 Oct. 2018. Accepted for publication 19 Oct. 2018.

This research was supported jointly by the State Bureau of Forestry 948 project (2014-4-14), Guangxi Key Laboratory of Special Non-wood Forest Cultivation and Utilization (project no. 18-A-03-01), the Distinguished Expert Special Fund provided by Guangxi Zhuang Autonomous Region, and Clemson University, Clemson, SC. ${ }^{1}$ Corresponding authors. E-mail: 13978899665@ 126.com or hliang@clemson.edu.
5 to 6 years for grafted plants to start setting flower buds (Chai et al., 2009; Jiang and Zhao, 1997). During the first few years after flowering starts, only a few floral buds can be produced. This long juvenile phase not only hinders conventional breeding, but also has an adverse impact on economic incomes for commercial producers and breeders. Driven by its scarcity, the price of golden camellia flower tea is about 30,000 Yuan $(\approx \$ 4600)$ per kilogram, whereas floral bud tea is about 20,000 Yuan $(\approx \$ 3000)$, according to $\mathrm{Su}$ (2010) and a report in China Daily (China Daily, 2014). It is noteworthy that $C$. chrysantha has been listed as a first-grade endangered species in China as a result of its dramatic decline in natural population size (Xu, 1995). Since the establishment of the state-level natural reserve, which is in the primary distribution areas of the species, raw materials for manufacturing camellia products are mainly from cultivated plants. Therefore, there is strong interest in inducing early flowering in golden camellias for earlier harvest.

Considerable studies have demonstrated that phytohormones can induce early flowering in many plant species. However, the effect varies with the plant species, its age, and concentration of phytohormones used. For instance, gibberellin 3 treatment can activate SUPPRESSOR OF CONSTANS1 (SOC1) to induce flowering in Arabidopsis (Moon et al., 2003), and reduce apple flowering rate (Zhang et al., 2016). With ethephon, Luo et al. (2013) successfully increased flower number in mature 15- to 20-year-old C. chrysantha seedlings. However, the optimal concentration for flower induction, 2.50 $\mathrm{mg} \cdot \mathrm{L}^{-1}$, caused smaller flowers and leaf area. Sprouting of new shoots was also severely affected with this concentration of $2.50 \mathrm{mg} \cdot \mathrm{L}^{-1}$. PBZ [(2RS,3RS)-1(4-chlorophenyl)-4,4dimethyl-2-(1H-1,2,4-triazol-1-yl)pentan-3-ol] is a triazole-type cytochrome $\mathrm{P}_{450}$ inhibitor that is used extensively in horticulture as a plant growth retardant and fungicide. This growth regulator has been found to be predominantly effective in inducing and manipulating flowering/fruiting in plant species such as mango (Blaikie et al., 2004; Yadav et al., 2005), Eucalyptus (Griffin et al., 1993), Consolida orientalis (Oriental knight's-spur) (Mansuroglu et al., 2009), plum (Oliveira and Browning, 1993), red camellia hybrids (Camellia $\times$ Williamsii) (Wilkinson and Richards, 1988), and grapes (Christov et al., 1995). According to a report on guava (Psidium guajava L.), PBZ was found more effective in increasing fruit number, fruit yield, yield efficiency, and fruiting density than ethephon (Brar and Bal, 2016).

In a previous study with 4-year-old $C$. chrysantha-grafted plants with $C$. osmantha as rootstock, we tested the effect of PBZ and urea fertilizer on flowering induction with a $4 \times 4$ factorial design: four dosages of urea $(1,3,5$, or $8 \mathrm{~g} /$ plant $)$ and four concentrations of PBZ $(50,150,350$, or $750 \mathrm{ppm})$ (Wei et al., 2017). It was found that combinations of $150 \mathrm{ppm}$ PBZ with $1 \mathrm{~g}$ urea and $350 \mathrm{ppm}$ 
PBZ with $3 \mathrm{~g}$ urea resulted in significant flowering in juvenile $C$. chrysantha-grafted plants without negative effects on vegetative growth and flower bud size, and without severe defoliation. In the current study, the goal was to elucidate the effects of PBZ on floral induction in juvenile $C$. chrysantha seedlings.

\section{Materials and Methods}

Plant materials and experiment design. Seeds of $C$. chrysantha were sown in Mar. 2013 and grown in nonwoven fabric garden bags (height, $30 \mathrm{~cm}$; diameter, $25 \mathrm{~cm}$ ) containing yellow podzolic soil, with a $\mathrm{pH}$ range of 4.5 to 6.0 . Healthy seedlings with uniform growth (height, $0.85-1.3 \mathrm{~m}$; basal diameter, $10.3-15.5 \mathrm{~mm}$ ) were selected for the study (Fig. 1A). Three levels of PBZ concentrations $(100,200$, or $300 \mathrm{ppm})$ were prepared with tap water, then $1 \mathrm{~L}$ of solution was applied to the garden bags on the mornings of 23 Mar. 2017 and 14 Apr. 2017. The control plants were managed in the same way as the treated group except with no PBZ applied to the garden bags. PBZ (CAS no. 76738-62-0) was purchased from Anyang Quanfeng Biological Technology Co. Ltd. (He Nan Province, China) and contained $95 \%$ active components.

Study site. The study was conducted in the Camellia Nursery of Guangxi Forestry Re- search Institute, China (lat. $22^{\circ} 56^{\prime} \mathrm{N}$, long. $108^{\circ} 21^{\prime} \mathrm{E}, 95$ m.a.s.1.). With a subtropical monsoon climate, the area has distinct dry and wet seasons. The average annual temperature is $21.8^{\circ} \mathrm{C}$, whereas the average in January is $11.8^{\circ} \mathrm{C}$, and $27.6^{\circ} \mathrm{C}$ in July. The recorded coldest and hottest temperatures are $-1.5{ }^{\circ} \mathrm{C}$ and $39.4{ }^{\circ} \mathrm{C}$, respectively. Annual accumulated temperature of at least $10^{\circ} \mathrm{C}$ is $7,200{ }^{\circ} \mathrm{C}$. The rainy season is during May to September, with an annual precipitation of more than $1300 \mathrm{~mm}$. All plants were maintained under a shade canopy that was $\approx 2.9 \mathrm{~m}$ aboveground and blocked $50 \%$ to $60 \%$ sunlight.

Sample and data collection. When floral buds started to open in Jan. 2018, floral buds and flowers were counted. Defoliation percentage was estimated and categorized into five groups: A, $<1 \%$; B, $(1 \%-5 \%$; C, $6 \%-$ $30 \%$; D, 31\%-40\%; E, 41\%-50\%; and F, $>50 \%$. Size (length and width) of at least four fully opened flowers (if available) and fresh weight were measured for each plant. Healthy young leaves (freshly opened from current-year shoots) and old leaves from the past year's growth were harvested from each plant and used for analyses of activities of stress-related enzymes [APX, CAT, polyphenol oxidase (PPO), SOD, and POD], and levels of MAD, chlorophylls, water-soluble sugar, and nutrients $(\mathrm{N}, \mathrm{P}, \mathrm{K}$, and $\mathrm{C}$ ).
Leaf samples without main midribs $(0.2 \mathrm{~g}$ per sample) were ground in liquid nitrogen into a fine powder and then extracted with a phosphate buffer ( $\mathrm{pH} 7.0$ ) containing $0.2 \mathrm{~mm}$ ethylenediamine tetra-acetic acid and 2\% polyvinylpyrrolidone. After centrifuging at $15,000 \mathrm{~g}$ for $20 \mathrm{~min}$ at $4{ }^{\circ} \mathrm{C}$, the supernatant was collected as the crude extract for analysis. Activity of APX was measured according to Nakano and Asada (1981) by monitoring the rate of ascorbate oxidation at $290 \mathrm{~nm}$. CAT activity was assayed in a reaction mixture containing $25 \mathrm{~mm}$ phosphate buffer ( $\mathrm{pH} 7.0), 10 \mathrm{~mm} \mathrm{H}_{2} \mathrm{O}_{2}$, and enzyme. The decomposition of $\mathrm{H}_{2} \mathrm{O}_{2}$ was followed at $240 \mathrm{~nm}$ absorbance. PPO activity was determined by measuring the initial rate of quinone formation, as indicated by an increase in absorbance at $420 \mathrm{~nm}$ (Wissemann and Lee, 1980). SOD activity was determined by photometric measurement of the product of the reduction of nitro blue tetrazolium (Giannopolitis and Ries, 1977). With guaiacol as a substrate, POD activity was assayed by recording an increase in absorbance at $470 \mathrm{~nm}$ as a result of the guaiacol oxidation (Hammerschmidt et al., 1982). MDA content was measured using thiobarbituric acid reactive substrates (Hodges et al., 1999).

For chlorophylls a and $\mathrm{b}, \approx 0.1 \mathrm{~g}$ of leaf tissue without main veins were placed into 1 $\mathrm{mL}$ acetone $(80 \%)$ and ethanol $(100 \%) \mathrm{mix}$ $(\mathrm{v} / \mathrm{v}=1: 1)$ for $30 \mathrm{~min}$. Extraction absorbance
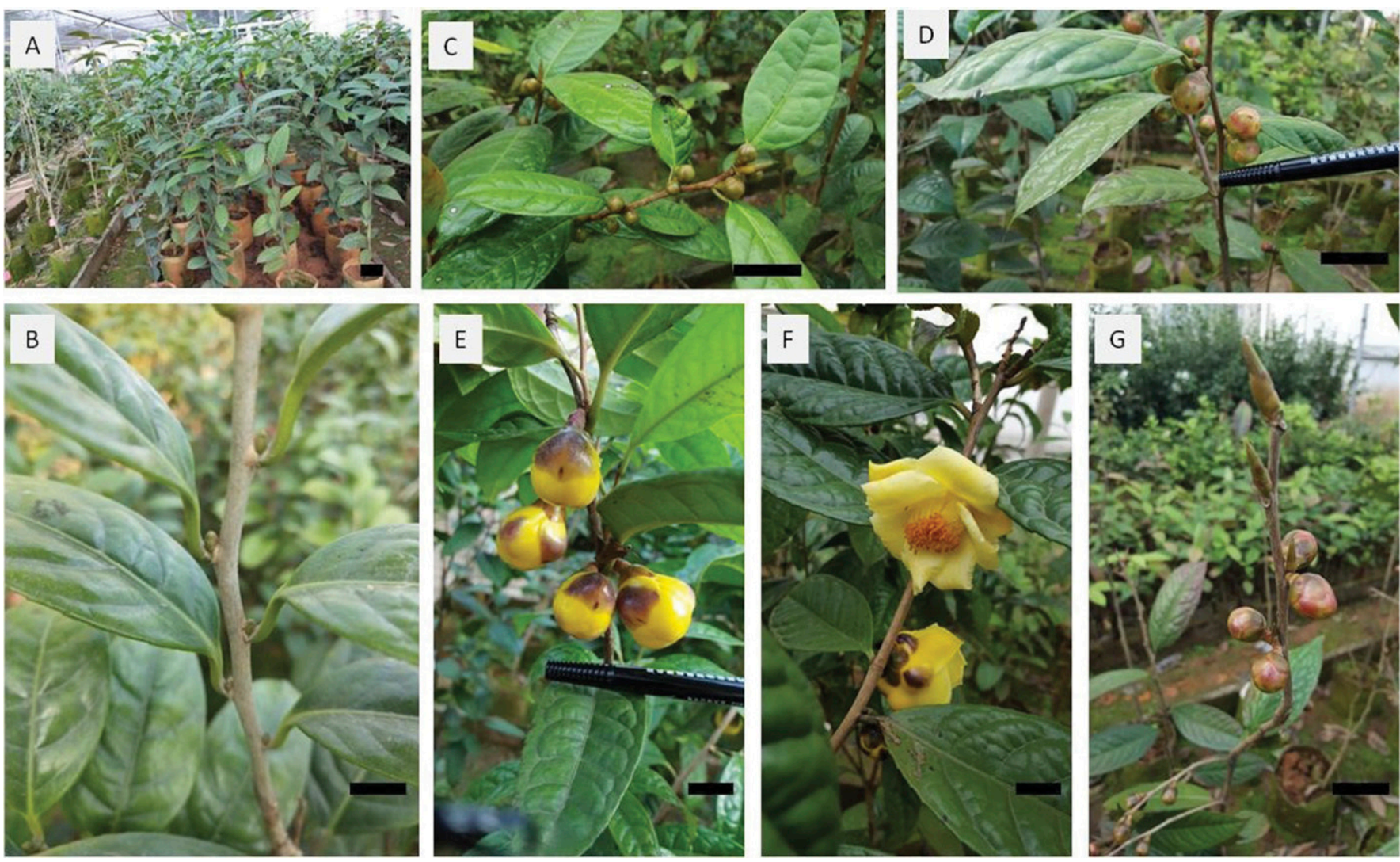

Fig. 1. C. chrysantha seedlings and their paclobutrazol (PBZ)-induced reproductive buds and flowers. (A) Four-year-old C. chrysantha seedlings in January 2017 before PBZ treatment. (B-E) Reproductive buds in (B) late May, (C) mid October, (D) mid December 2017, and (E) early 2018. (F) Fully opened flowers in late Jan. 2018. (G) A 300 ppm-treated plant with severe defoliation in mid Dec. 2017. The scale bars represent $10 \mathrm{~cm}$ in each panel. 
at $663 \mathrm{~nm}$ and $646 \mathrm{~nm}$ was recorded in a ultraviolet-Vis spectrophotometer (model U2900; Hitachi Co., Tokyo, Japan). Chlorophyll content was calculated as described in Porra et al. (1989) and was measured as milligrams per gram leaf fresh weight. For water-soluble sugars, $\approx 0.1 \mathrm{~g}$ of leaf tissue was boiled in double-distilled water for $30 \mathrm{~min}$ followed by anthrone-sulfuric acid reagent for $1 \mathrm{~min}$ (Brink et al., 1960). Sucrose was used as the standard, and absorbance was read at $630 \mathrm{~nm}$. Water-soluble sugars were measured as percentage of leaf fresh weight. Analyses of enzyme activities and contents of chlorophylls and water-soluble sugars were conducted by a facility in the College of Forestry, Guangxi University, Nanning, China.

$\mathrm{C}, \mathrm{N}$, and $\mathrm{P}$ contents were determined by standard $\mathrm{K}_{2} \mathrm{Cr}_{2} \mathrm{O}_{7} / \mathrm{H}_{2} \mathrm{SO}_{4}$ oxidation, Kjeldahl, and $\mathrm{NaHCO}_{3}$ extraction/molybdenumantimony anticolorimetric methods, respectively. Inductively coupled plasma-atomic emission spectrometry was used for $\mathrm{K}$ analysis. Nutrient contents were calculated as milligrams per kilogram dry weight. Sample preparation and measurement were performed by a core facility at Guangxi Forestry Research Institute (Nanning, China).

Fully open flowers were collected from each plant, dried in a lyophilizer (Heto FD3 freeze dryer; Heto-Holten A/S, Copenhagen, Denmark), and ground into a fine powder. Pharmacologically active compounds were analyzed in a core facility at Guangxi Forestry Research Institute (Nanning, China). Total flavonoids were extracted with $70 \%$ ethanol and measured using the aluminum nitrate colorimetric method, with absorbance taken at $500 \mathrm{~nm}$ (Wang et al., 2012). For crude saponins, flowers were heated in $\mathrm{ddH}_{2} \mathrm{O}$ at $80{ }^{\circ} \mathrm{C}$ and the extracts were purified with ethanol and diethyl ether as described in Shah et al. (2014). Determination of the total saponin content was conducted using the colorimetric method as described in Murakami et al. (2013). The reaction reagents included vanillin, perchloric acid, and glacial acetic acid. Absorbance wavelength was $540 \mathrm{~nm}$. Polysaccharides were measured with the standard phenol-sulfuric acid reaction method, and absorbance was taken at $490 \mathrm{~nm}$ (Dubois et al., 1956). Polyphenols were extracted with $70 \%$ methanol and determined using the Folin-Ciocalteu method (Turkmen et al., 2006). The absorbance wavelength was $765 \mathrm{~nm}$. The analyses of chemical components in flowers were performed by a facility in the College of Forestry, Guangxi University, Nanning, China. The control flowers were from a 35-year-old C. chrysantha plant.

Data analysis. A completely randomized design was used in the experiments. There were four plants per treatment type and control. All chemical analyses were conducted individually with each plant unless indicated otherwise. For each biologic sample, there were three technical replicates. All statistical analyses were performed using SPSS (version 17.0; IBM, Armonk, NY), and significance was set at
$P<0.05$, as previously reported in Wei et al. (2017).

\section{Results and Discussion}

Successful early flower induction with $P B Z$. Reproductive buds started to become visible in late May 2017, which are usually rounder than vegetative buds (Fig. 1B). The reproductive buds continued to enlarge for the remaining months of the year (Fig. 1CE). Blossoming started in early January and lasted for 2 months (Fig. 1F). None of the control plants flowered in 2018. In comparison, $75 \%$ of the $100-\mathrm{ppm}-$ and $200-\mathrm{ppm}-$ treated plants, and all the 300-ppm-treated plants produced floral buds. The average number of floral buds per plant induced by PBZ was 20, and there was no statistical difference among the three levels of PBZ concentration. The results are similar to the ones from $C$. chrysantha grafted plants. When treated with PBZ, C. chrysantha grafted plants produced a range of 9 to 33 floral buds per plant, depending on the PBZ concentration and its combination with urea (Wei et al., 2017). Thus, it is corroborated that PBZ is an effective flower inducer for $C$. chrysantha juvenile plants. In the experiment conducted in 2016 (Wei et al., 2017), it was found that $33 \%$ of the plants that flowered in 2017 continued to flower in 2018 , although they did not receive PBZ treatment in 2017.

It is notable that size and fresh weight of PBZ-induced flowers were smaller than the ones from a 35-year-old $C$. chrysantha plant (31.9 vs. $46.0 \mathrm{~mm}, 4.75$ vs. $6.9 \mathrm{~g}$, respectively), whereas their dry weight was similar $(0.82$ vs. $0.71 \mathrm{~g})$. There was no statistical differences among the three levels of PBZ concentration in terms of flower size, and fresh and dry weights. Similar to the observations in grafted $C$. chrysantha plants (Wei et al., 2017), defoliation occurred in PBZtreated seedlings in this study. Although the 100 -ppm-treated plants lost less than $30 \%$ of their leaves, the 200- and 300-ppm-treated seedlings lost $\approx 40 \%$ to $50 \%$ and more than $50 \%$ of leaves, respectively. There existed a strong correlation between severity of defoliation and PBZ concentration (absolute $R$ value, $0.87 ; P$ value, $<0.01$ ). It is well known that environmental stresses, such as drought, poor nutrition, and defoliation, can stimulate flowering. For instance, $50 \%$ and $75 \%$ defoliation in kiwifruit vines could lead to about a $25 \%$ and $53 \%$ increase in flower number, respectively (Cruz-Castillo et al., 2010). This stress-induced flowering may involve salicylic acid, the flowering gene FLOWERING LOCUS T, or both (Takeno, 2012). However, we did not observe a significant correlation between defoliation severity and flower bud number in the current study (absolute $R$ value $0.41 ; P$ value $>0.1)$. In the previous study with grafted $C$. chrysantha plants, there existed a weak positive correlation (absolute $R$ values $<0.35 ; P$ value $<0.05$ ) (Wei et al., 2017).

Plant growth, chlorophyll content, watersoluble sugars, and nutrients. When plant height and basal diameter were compared, a significant difference was not found between the treated and control plants, nor was one found among the treated ones. This is consistent with the previous study on grafted $C$. chrysantha when treated with comparable PBZ concentrations (Wei et al., 2017). As a growth retardant, PBZ inhibits plant height and diameter, as well as bud, leaf, and fruit size, when applied in high concentrations, as documented in numerous studies (e.g., Mabvongwe et al., 2016; Pal et al., 2016; Wei et al., 2017). Similarly, there was no significant difference in chlorophyll $\mathrm{a}$ and $\mathrm{b}$ content in young leaves among the treatments and control. However, the 200-ppm treatment decreased both the chlorophyll $\mathrm{a}$ and $\mathrm{b}$ levels significantly, by $20 \%$ and $26 \%$, respectively, in old leaves when compared with the untreated control (Fig. 2).

PBZ seemed to decrease water-soluble sugar content in old leaves; however, the reduction was not statistically significant $(P>$ $0.05)$. Total $\mathrm{C}$ content in both young and old leaves was also similar among control and PBZ treatments, with an average of $454 \pm$ $14.5 \mathrm{~g} / \mathrm{kg}$. These results are consistent with the fact that chlorophyll $\mathrm{a}$ and $\mathrm{b}$ content in young leaves is not significantly affected by the PBZ concentrations used in our study. PBZ-treated plants contained similar levels of $\mathrm{N}, \mathrm{P}$, and $\mathrm{K}$, with the exception of the 300 ppm treatment, which increased the $\mathrm{N}$ level significantly in young leaves (Fig. 3). Severe defoliation might have contributed to the increased $\mathrm{N}$ level in young leaves of 300ppm-treated plants as a result of fewer $\mathrm{N}$ sinks competing for $\mathrm{N}$. Accumulation of $\mathrm{N}, \mathrm{P}$, and $\mathrm{K}$ decreased in old leaves compared with young ones in the control plants. This pattern remained unchanged by PBZ. These data support the observation that the PBZ concentrations used in the study did not affect vegetative growth.

Effects of PBZ on pharmacologically active compounds in flowers. Golden camellia flowers are commonly used for tea products. It is critical that PBZ treatment does not affect negatively the healthy beneficial compounds. Compared with control flowers from a 35-year-old $C$. chrysantha plant, PBZ decreased polysaccharide content by about $37.5 \%$, but increased the saponin level 2.2 times (Fig. 4). For polyphenols, 100 ppm showed a negative effect (a 14\% decrease), whereas greater concentrations showed no effects. The 200-ppm PBZ treatment increased the total flavonoid level by $27.0 \%$, whereas the 100- and 300-ppm treatments did not result in a significant change.

It is notable that various factors, such as cultivar, plant age, climate, and cultivation management, can affect the composition of chemical constituents. For instance, reports of polyphenol content in C. chrysantha flowers ranged from 40.8 to $130 \mathrm{mg} / \mathrm{g}$ (Lin et al., 2010; Niu et al., 2015; Su et al., 2014; Tang et al., 2009). In our study, the PBZinduced flowers contained $117 \mathrm{mg} / \mathrm{g}$, whereas naturally occurring flowers had $124 \mathrm{mg} / \mathrm{g}$, within the aforementioned range. The naturally 


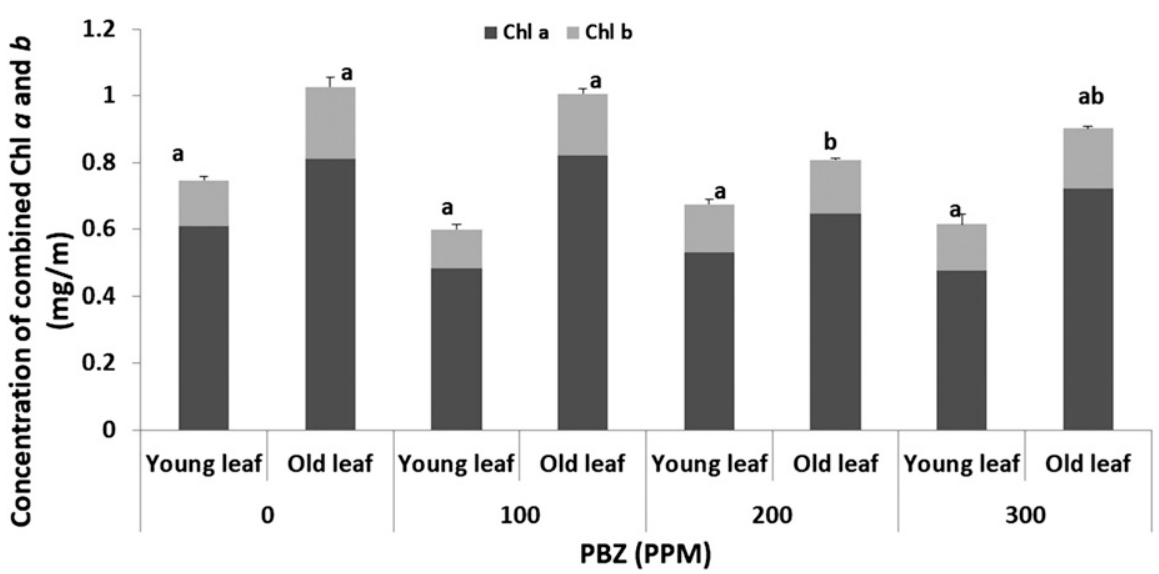

Fig. 2. Chlorophyll (Chl) concentrations in young (freshly opened from current-year shoots) and old leaves from the past year's growth of paclobutrazol (PBZ)-treated and untreated C. chrysantha plants. Samples were collected in Jan. 2018. Different letters within the same age group indicate significant a difference at $P<0.05$. The bars indicate SD.

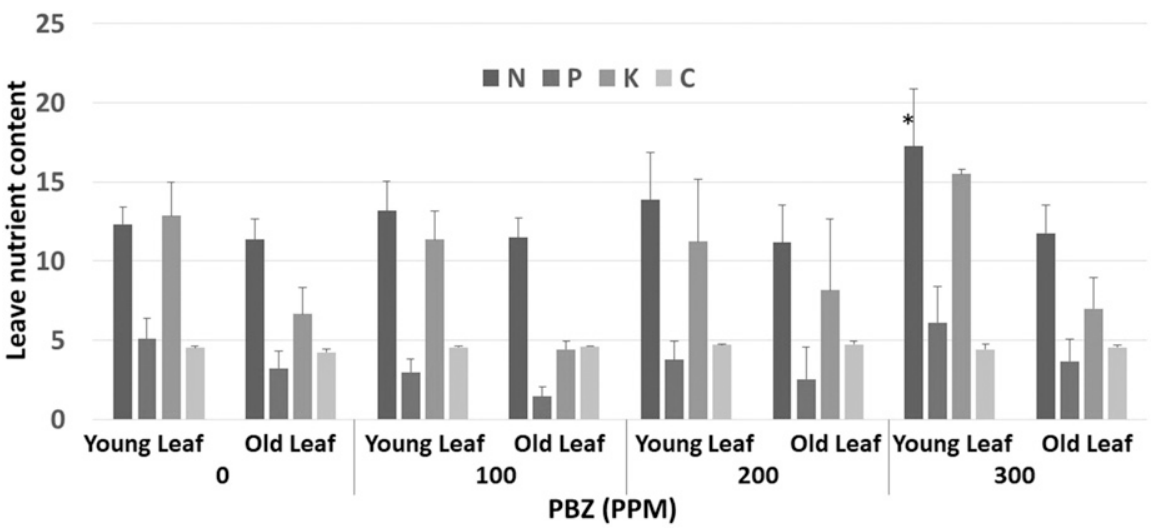

Fig. 3. Contents of nitrogen $(\mathrm{N})$, phosphorus $(\mathrm{P})$, potassium $(\mathrm{K})$, and carbon $(\mathrm{C})$ in leaves of paclobutrazol (PBZ)-treated and untreated C. chrysantha seedlings. Samples were collected in Jan. 2018. Concentration for N, P, K is measured in grams per kilogram, and 100 grams per kilogram for C. *Significant difference from control at $P<0.05$. The bars indicate SD.

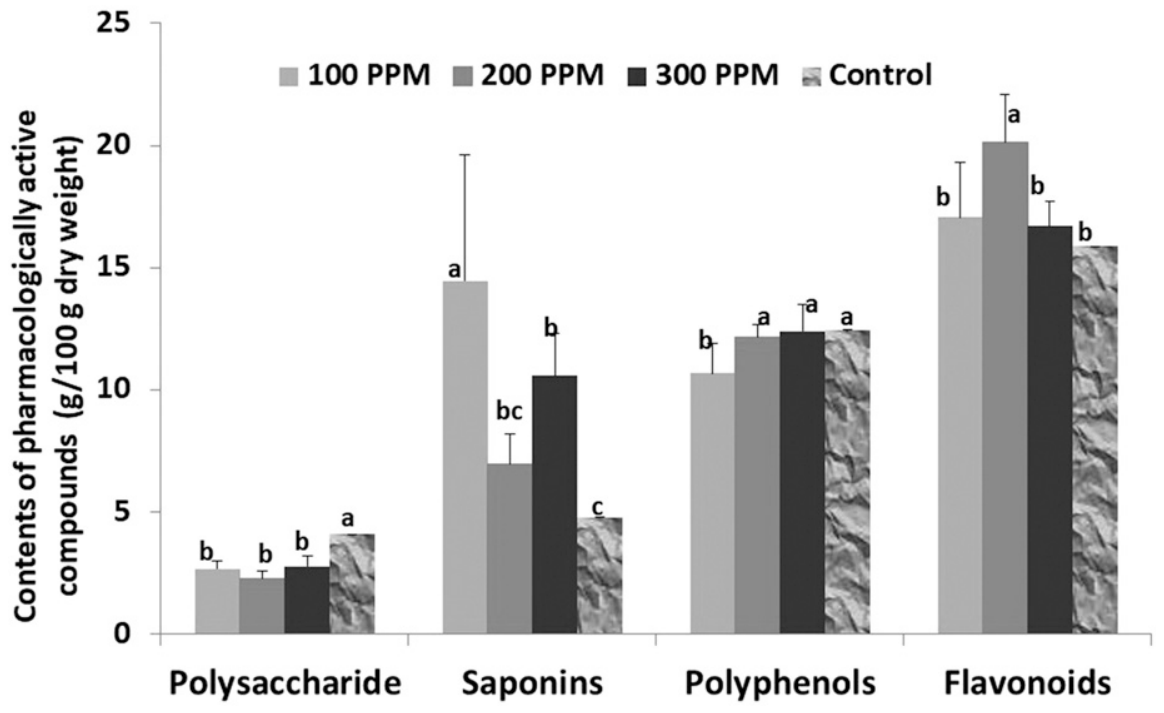

Fig. 4. Contents of flavonoids, saponins, polyphenols, and polysaccharide in flowers of paclobutrazoltreated and naturally flowering (control) C. chrysantha plants. Samples were collected in Jan. 2018. Within the same chemical compound, different letters indicate a significant difference at $P<0.05$.

occurring flowers in our study had a greater polysaccharide content $(40.8 \mathrm{mg} / \mathrm{g})$ than the ranges reported by Niu et al. (2014) and Tang et al. (2017), which were 32.8 and $21.4 \mathrm{mg} / \mathrm{g}$, respectively. However, the PBZ-induced flowers contained a polysaccharide level $(25.5 \mathrm{mg} / \mathrm{g})$ similar to the reports. Niu et al. (2015) reported a level of $114 \mathrm{mg} / \mathrm{g}$ saponins in C. chrysantha flowers, similar to what we detected in PBZ-induced flowers $(106 \mathrm{mg} / \mathrm{g})$. As for flavonoids, both PBZ-induced and naturally occurring flowers in our study showed a comparable level to the report by Niu et al. (2015): 180, 159, and $136.3 \mathrm{mg} / \mathrm{g}$ respectively. Overall, PBZ did not change significantly the levels of beneficial compounds in the induced flowers.

Stress caused by PBZ. PBZ treatment causes defoliation, and there exists a strong correlation between severity of defoliation and PBZ concentration. When commonly used stress-related markers (APX, CAT, PPO, SOD, POD, and MAD) were examined (Fig. 5), it was found that PBZ treatment did not have an effect on POD, regardless of leaf age. Levels of CAT and APX increased in both young and old leaves of plants treated with 200 and $300 \mathrm{ppm}$. All three PBZ concentrations used resulted in an enhancement in SOD activity in young leaves, but no effect in old leaves was significant. PPO decreased in young leaves of 200- and 300ppm-treated plants, and decreased in old leaves of all PBZ-treated plants. In comparison, $300 \mathrm{ppm}$ PBZ increased the MDA level in young leaves significantly, whereas 200 and $300 \mathrm{ppm}$ decreased its level in old leaves. Overall, 300-ppm-treated plants suffered the most severe defoliation: Two of the treated plants lost most of their leaves by January and died by May 2018. Consistent with defoliation severity, young leaves of 300-ppm-treated plants contained significantly greater levels of CAT and APX than 100-ppm-treated plants, and their MDA content was significantly greater than both 100- and 200-ppm-treated plant.

Various stresses can induce oxidative damage in plants, in which reactive oxygen species, such as superoxide radical $\left(\mathrm{O}_{2} \cdot{ }^{-}\right)$, hydroxy radical $(. \mathrm{OH})$, hydrogen peroxide $\left(\mathrm{H}_{2} \mathrm{O}_{2}\right)$, and alkoxy radical (RO.), are produced. The toxic superoxide radical is usually dismutated rapidly by SOD to $\mathrm{H}_{2} \mathrm{O}_{2}-\mathrm{a}$ product that is relatively stable and can be detoxified by CAT and peroxidases. SOD, POX, APX, CAT, and PPO are enzymatic antioxidants that participate in alleviation of oxidative damage (Prochazkova et al., 2001), and their activities generally increase under stress (Shigeoka et al., 2002). Our results generally follow this trend, except for POD and PPO, and there existed a difference in reaction between young and old leaves. MDA results from lipid peroxidation of polyunsaturated fatty acids is an indicator of free radical production and consequent tissue damage. Our data indicate that $300 \mathrm{ppm}$ PBZ resulted in significant oxidative lipid damage in young leaves.

To conclude, PBZ is an effective flowering inducer for juvenile $C$. chrysantha, and $100 \mathrm{ppm}$ provides the best results in seedlings in comparison with greater concentrations. Although the induced flowers were smaller than the ones from mature trees, there were no significant changes in the contents of pharmacologically active compounds 

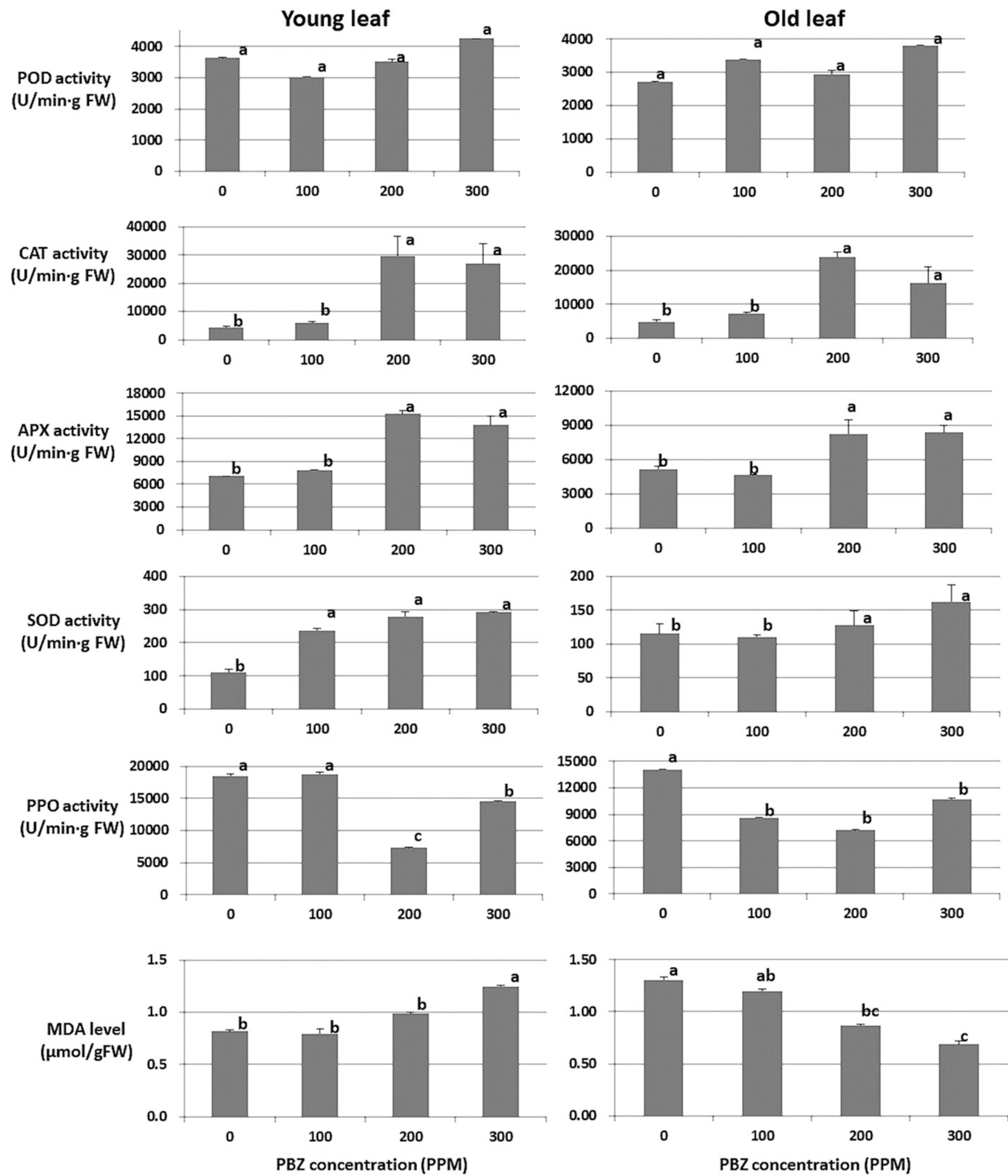

Fig. 5. Activities of peroxidase (POD), catalase (CAT), ascorbate peroxidase (APX), superoxide dismutase (SOD), and polyphenol oxidase (PPO), and level of malondialdehyde (MAD) in young and old leaves of paclobutrazol-treated and untreated C. chrysantha plants. Samples were collected in Jan. 2018. Within each graph, different letters indicate significant difference at $P<0.05 . \mathrm{FW}=$ fresh weight.

(polysaccharide, polyphenols, flavonoids, and saponins). Thus, PBZ treatment does not affect $C$. chrysantha flowers' medicinal value. PBZ is a growth retardant; however, the concentrations effective in flowering induction in $C$. chrysantha had no negative effect on the current year's growth in height and basal diameter. Severe defoliation is a major concern, considering that it not only may cause stunted or malformed plants, and even death to the plant in the long term, but also it reduces the plant's aesthetic appeal. In addition, leaves of golden camellias are valued for tea. PBZ treatment led to enhanced stress, which might be a key contributing factor for defoliation. Currently, an investigation is being undertaken to study whether reducing treatment frequency (from twice to once) and 
solution volume applied (from $1 \mathrm{~L}$ to $0.5 \mathrm{~L}$ ) will lessen the effect of PBZ on defoliation. In future studies it would be informative to investigate the changes of endogenous hormones, such as auxins, gibberellins, cytokinins, ethylene, and abscisic acid, during bud differentiation after PBZ treatment.

\section{Literature Cited}

Brar, J.S. and J.S. Bal. 2016. Role of paclobutrazol and ethephon in reproductive growth of 'Allahabad Safeda' guava (Psidium guajava L.) plants at different spacing. J. Hort. Sci. 5:128-133.

Blaikie, S.J., V.J. Kulkarni, and W.J. Müller. 2004. Effects of morphactin and paclobutrazol flowering treatments on shoot and root phenology in mango cv. Kensington Pride. Scientia Hort. 101:51-68.

Brink, R.H.J., P. Dubach, and D.L. Lynch. 1960. Measurement of carbohydrates in soil hydrolyzates with anthrone. Soil Sci. 89:157-166.

Chai, S.F., X. Wei, Y.S. Jiang, J.Q. Wei, S.Y. Jiang, and M.L. Wang. 2009. The flowering phenology and characteristics of reproductive modules of endangered plant Camellia nitidissina. Redai Yaredai Zhiwu Xuebao 17:5-11 (in Chinese with English abstract).

China Daily. 2014. Golden Camilla. 15 Nov. 2018. $<$ http://guangxi.chinadaily.com.cn/hechi/201409/05/content_18551816.htm>.

Christov, C., I. Tsvetkov, and V. Kovachev. 1995. Use of paclobutrazol to control vegetative growth and improve fruiting efficiency of grapevines (Vitisvinifera L.). Bulg. J. Plant Physiol. 21:64-71.

Cruzcastillo, J.G., D.J. Woolley, and F. Famian. 2010. Effects of defoliation on fruit growth, carbohydrate reserves and subsequent flowering of 'Hayward' kiwifruit vines. Scientia Hort. 125:579-583.

Dubois, M., K.A. Gilles, J. Hamilton, P.A. Rebens, and F. Smith. 1956. Colorimetric method for determination of sugars and related substances. Anal. Chem. 28:350-356.

Giannopolitis, N. and S.K. Ries. 1977. Superoxide dismutase: I. Occurrence in higher plants. Plant Physiol. 59:309-314.

Griffin, A.R., P. Whiteman, T. Rudge, I.P. Burgess, and M. Moncur. 1993. Effect of paclobutrazol on flower-bud production and vegetative growth in two species of Eucalyptus. Can. J. For. Res. 23:640-647.

Guo, J. 2010. Five kinds of items listed as new members in source of food catalogue. Farm. Prod. Process. 6:39 (in Chinese with English abstract).

Hammerschmidt, R., E.M. Nuckles, and J. Kuć. 1982. Association of enhanced peroxidase activity with induced systemic resistance of cucumber to Colletofrichum lagenarium. Physiol. Plant Pathol. 20:73-82.

He, D., X. Li, X. Sai, L. Wang, S. Li, and Y. Xu. 2018a. Camellia nitidissima C.W. Chi: A review of botany, chemistry, and pharmacology. Phytochem. Rev. 17:327-349.

He, D., X. Sai, N. Wang, X. Li, L. Wang, and Y. Xu. 2018b. Camellia euphlebia exerts its antidepressant-like effect via modulation of the hypothalamic-pituitary-adrenal axis and brain monoaminergic systems. Metab. Brain Dis. 33:301-312.

Hodges, D.M., J.M. DeLong, C.F. Forney, and R.K. Prange. 1999. Improving the thiobarbituric acid-reactive-substances assay for estimating lipid peroxidation in plant tissues containing anthocyanin and other interfering compounds. Planta 207:604-611.
Jiang, S. and R. Zhao. 1997. Observation on biological characteristics of Camellia parvipetala. Guihaia 17:94-96 (in Chinese with English abstract).

Lin, H.J., X.M. Qin, Q.W. Zeng, J.Z. Yang, and J.M. Zhong. 2010. Analysis on chemical and bioactive components in flower of Camellia chrysantha $(\mathrm{Hu})$. Tuyama. Food Sci. Technol. 35:88-91 (In Chinese with English abstract).

Luo, C.X., H. Pan, and W.H. Liang. 2013. Effects of ethephon on flowering of camellia sect. Chrysantha Chang. Guangxi For. Sci. 42:276278 (in Chinese with English abstract).

Mabvongwe, O., B.T. Manenji, M. Gwazane, and M. Chandiposha. 2016. The effect of paclobutrazol application time and variety on growth, yield, and quality of potato (Solanum tuberosum L.). Adv. Agr. doi: 10.1155/2016/1585463.

Mansuroglu, S., O. Karaguzel, V. Ortacesme, and M.S. Sayan. 2009. Effect of paclobutrazol on flowering, leaf and flower colour of Consolida orientalis. Pak. J. Bot. 41:2323-2332.

Moon, J., S.S. Suh, H. Lee, K.R. Choi, C.B. Hong, N.C. Paek, S.G. Kim, and I. Lee. 2003. The SOC1 MADS-box gene integrates vernalization and gibberellin signals for flowering in $\mathrm{Arab}$ idopsis. Plant J. 35:613-623.

Murakami, A.N.N., R.D.M.C. Amboni, E.S. Prudêncio, E.R. Amante, C.B. Fritzen-Freire, B.C.B. Boaventura, I.B. Muñoz, C.S. Branco, M. Salvador, and M. Maraschin. 2013. Concentration of biologically active compounds extracted from Ilex paraguariensis St. Hil. by nanofiltration. Food Chem. 141:60-65.

Nakano, Y. and K. Asada. 1981. Hydrogen peroxide is scavenged by ascorbate-specific peroxidase in spinach chloroplasts. Plant Cell Physiol. $22: 867-880$

Niu, G.J., J.H. Hao, S. Zhu, W.H. Wang, Q.Y. Chen, and Y.C. Liang. 2015. Determination of active ingredients and antioxidant activities of Camellia sect. Chrysantha by QAMS. J. For. Environ. 35:165-168 (In Chinese with English abstract).

Niu, G.J., S. Zhu, Q.Y. Chen, T.Z. Chen, X.S. Chen, and Y.C. Liang. 2014. Determination of polysaccharides and antioxidant activity of different parts of Camellia nitidissima. Zhongguo Shiyan Fangjixue Zazhi 20:168-172 (In Chinese with English abstract).

Oliveira, C.M. and G. Browning. 1993. Studies on the induction of flowering in juvenile Prunusavium L. J. Hort. Sci. 68:731-739.

Pal, S., J. Zhao, A. Khan, N.S. Yadav, A. Batushansky, S. Barak, B. Rewald, A. Fait, N. Lazarovitch, and S. Rachmilevitch. 2016. Paclobutrazol induces tolerance in tomato to deficit irrigation through diversified effects on plant morphology, physiology and metabolism. Sci. Rpt. 6:39321.

Porra, R.J., W.A. Thompson, and P.E. Kriedemann. 1989. Determination of accurate extinction coefficients and simultaneous equations for assaying chlorophylls $\mathrm{a}$ and $\mathrm{b}$ extracted with four different solvents: Verification of the concentration of chlorophyll standards by atomic absorption spectroscopy. BBA Bioenerg. 975:384-394.

Prochazkova, D., R.K. Sairam, G.C. Srivastava, and D.V. Singh. 2001. Oxidative stress and antioxidant activity as the basis of senescence in maize leaves. Plant Sci. 161:765-771.

Shah, S.M.M., A. Sadiq, S.M.H. Shah, and S. Khan. 2014. Extraction of saponins and toxicological profile of Teucrium stocksianum boiss extracts collected from District Swat, Pakistan. Biol. Res. 47:65.

Shigeoka, S., T. Ishikawa, M. Tamoi, Y. Miyagawa, T. Takeda, Y. Yabuta, and K. Yoshimura. 2002.
Regulation and function of ascorbate peroxidase isoenzymes. J. Expt. Bot. 53:1305-1319.

$\mathrm{Su}, \mathrm{K} .2010$. Development of golden camellias in Guangxi. J. Guangxi Agr. 25:98-100. (In Chinese with English abstract).

Su, J.M., X.M. Wang, Z.Z. Mo, and S.Z. Lei. 2014. Determination and analysis the content of tea polyphenols and total flavonoids in flower of three Camellia chrysantha. J. Yulin Normal Univ. 35:64-68. (In Chinese with English abstract).

Takeno, K. 2012. Stress-induced flowering, p. 331345. In: P. Ahmad and M.N.V. Prasad (eds.). Abiotic stress responses in plants: Metabolism, productivity and sustainability. Springer, New York, NY

Tang, Q., Y.Y. Luo, L.D. Huang, M.Z. Lu, L. Tang, L.Y. Shi, B.M. Feng, and Y.Q. Wang. 2009. Determination of chemical constituents in section Chrysantha Chang. Lishizhen Med. Mater. Med. Res. 20:769-771 (In Chinese with English abstract).

Tang, J.M., Y.C. Shi, Y.Q. Liao, J.S. Fan, J.Q. Wei, X.Y. Wen, and X. Wei. 2017. Analysis of chemical components in flowers of Camellia nitidissima. Guihaia 37:1176-1181 (In Chinese with English abstract).

Turkmen, N., F. Sari, and Y.S. Velioglu. 2006. Effects of extraction solvents on concentration and antioxidant activity of black and black mate tea polyphenols determined by ferrous tartrate and Folin-Ciocalteu methods. Food Chem. 99:835-841.

Wang, W., H. Liu, Z. Wang, J. Qi, S. Yuan, W. Zhang, H. Chen, J.W. Finley, L. Gu, and A.Q. Jia. 2015. Phytochemicals from Camellia nitidissima Chi inhibited the formation of advanced glycation end-products by scavenging methylglyoxal. Food Chem. 205: 204-211.

Wang, J., Y.M. Zhao, C.Y. Guo, S.M. Zhang, C.L. Liu, D.S. Zhang, and X.M. Bai. 2012. Ultrasound-assisted extraction of total flavonoids from Inula helenium. Pharmacogn. Mag. 8:166-170

Wei, X.J., J. Ma, K.X. Li, X.J. Liang, and H. Liang. 2017. Flowering induction in Camellia chrysantha, a golden Camellia species, with paclobutrazol and urea. HortScience 52:1537-1543.

Wilkinson, R.L. and D. Richards. 1988. Influence of paclobutrazol on the growth and flowering of Camellia $\times$ Williamsii. HortScience 23:359360.

Wissemann, K.W. and C.Y. Lee. 1980. Purification of grape polyphenoloxidase with hydrophobic chromatography. J. Chromatogr. 192: 232-235.

$\mathrm{Xu}$, Z.R. 1995. A study of the vegetation and floristic affinity of the limestone forests in southern and southwestern China. Ann. Mo. Bot. Gard. 82:570-580.

Yadav, R.K., N. Rai, D.S. Yadav, and B.S. Asati. 2005. Use of paclobutrazol in horticultural crops: A review. Agr. Rev. (Karnal) 26:124132.

Zhang, S., D. Zhang, S. Fan, L. Du, Y. Shen, L. Xing, Y. Li, J. Ma, and M. Han. 2016. Effect of exogenous $\mathrm{GA}_{3}$ and its inhibitor paclobutrazol on floral formation, endogenous hormones, and flowering-associated genes in 'Fuji' apple (Malus domestica Borkh.). Plant Physiol. Biochem. 107: 178-186.

Zhuang, R.L. 2008. Chinese oil-tea Camellia. 2nd ed. Chinese Forestry Publishing House, Beijing, China. 